\title{
TỬ VONG SƠ SINH VÀ MộT SỐ CAN THIỆP HIỆ QUẢ GIẢM TỬ VONG TRONG Lộ TRÌNH HƯớNG TỚI MỤC TIÊU CẢI THIỆN SỨC KHỎE SO SINH VÀO NĂM 2030
}

Đinh Thị Phương Hòa

\section{TÓM TẮT}

Số trẻ sơ sinh tử vong trên toàn cầu đã giảm từ 2,7 triệu năm 2015 xuống 2,4 triệu năm 2020. Tuy nhiên, tốc độ giảm tử vong sơ sinh chậm và hiện nay chiếm tới $44 \%$ trong số tử vong trẻ dưới 5 tuổi. Vi thế, giảm tử vong sơ sinh được đưa vào trong mục tiêu 3 của mục tiêu phát triển bên vứng hậu thiên niên kỷ (SDGs) với chỉ tiêu là chấm dứt các trường hợp tử vong sơ sinh do các nguyên nhân có thể phòng tránh được vào năm 2030.

Ở Việt Nam, cũng tương tự như thực trạng ở các nước thu nhập và trung bình khác, tử vong sơ sinh tuy có giảm trong những năm gân đây nhưng vẫn chậm so với những thành tựu nổi bật trong giảm tử vong trẻ em. Một số khó khăn chính trong cải thiện sức khoẻ sơ sinh là sự khác biệt giữa các vùng, miền; chất lượng chăm sóc chưa đáp ứng được nhu câuu và các chương trình chăm sóc sơ sinh chưa đến được hết những đối tượng cần nhất. Nhà nước cũng đã xác định được sự cân thiết phải giảm tử vong sơ sinh và hiện đang nỗ lực đẩy nhanh các hoạt động can thiệp hiệu quả hơn. Các can thiệp và phương pháp tiếp cận dựa trên bằng chứng có thể ngăn chặn được tử vong sơ sinh bao gồm chăm sóc bà mẹ trong thời gian mang thai, cuộc đẻ và sau đẻ. Gói can thiệp có hiệu quả nhất để có thể chấm dứt những tử vong do các nguyên nhân có thể phòng được là chăm sóc trong thời gian chuyển dạ, tại cuộc đẻ và trong vòng 1 tuần sau đẻ; chăm sóc các trẻ đẻ non/nhẹ cân và sơ sinh bệnh lý. Mở rộng độ bao phủ, cải thiện chất lượng chăm sóc theo tiếp cận chăm sóc liên tục, bảo đảm công bằng cho mọi bà mẹ và trẻ sơ sinh bao gồm cả vấn đề tài chính. Đó là những can thiệp chính mà mỗi quốc gia cân đâu tư mới có thể giảm tử vong sơ sinh thành công.

\section{SUMMARY}

\section{NEONATAL MORTALITY, CURRENT SITUATION AND SOME EFFECTIVE INTERVENTIONS TO REACH THE GOAL OF IMPROVING NEWBORN HEALTH IN 2030}

Since 2015, the number of neonatal deaths in the World declined from 2.7 million to 2.4 million in 2020. However, the decline in neonatal mortality is slow and now accounts for $44 \%$ of all deaths among children younger than 5 years old. Reducing neonatal mortality, thereforewas put in the third Sustainable Development Goal (SDG), to end preventable newborn deaths by the year 2030.

Viet Nam is similar as other low- and middle-income countries, neonatal mortality have fallen in recent years but still lag behind the impressive gains made for child mortality. The main obstacles in improving neonatal heath are disparities between areas; quality of care is not meeting the

Nhận bài: 20-3-2021; Chấp nhận: 15-4-2021

Người chịu trách nhiệm: Đinh Thị Phương Hòa

Đị chi: Đt: 0913075058 
requirements and the neonatal health programs do not reach to those who need it the most. Reducing neonatal mortality has been recognized and the country is trying to take more progress in action.

Evidence - based interventions and approaches that prevent newborn deaths including care mothers during pregnancy; around delivery and postnatal care. The most greatest impact on ending preventable neonatal deaths include: care during labour, childbirth and the first week of life; and care for the small and sick newborn. Improve coverage and quality of carewithin the continuum of care, ensure equitable care to every woman and newborn baby including universal financial protection. No country can success in reducing neonatal mortality without this investment.

\section{1. ĐặT VẤN ĐỀ}

Tổng kết quá trình thực hiện Mục tiêu Thiên niên kỷ (MDGs), tử vong trẻ em (TVTE) dưới 5 tuổi trên toàn cầu giảm từ 12,7 triệu năm 1990 xuống còn 5,9 triệu năm 2015. Mặc dù không đạt được chỉ tiêu là giảm 2/3 số tử vong nhưng qua chặng đường 25 năm thực hiện, tất cả các quốc gia ký cam kết đã giảm được $53 \%$ số TVTE dưới 5 tuổi là một thành tựu đáng ghi nhận. Tuy nhiên, trong khi TVTE dưới 5 tuổi giảm đáng kể thì tử vong trẻ sơ sinh (TVSS) lại giảm chậm hơn. Cùng trong giai đoạn thực hiện MDGs, TVSS chỉ giảm được $47 \%$ (từ $36 \%$ xuống $19 \%$ ) và hiện vẫn chiếm đến 40\% TVTE dưới 5 tuổi [1].

Tại sao TVSS giảm chậm? câu hỏi đã được nhiều nhà nghiên cứu đặt ra và câu trả lời cũng đã nhận được hầu hết sự đồng thuận đó là do 2 lý do chính cản trở các can thiệp giảm TVSS. Thứ nhất là vì các nguyên nhân chính gây tử vong sơ sinh (đẻ non, ngạt, nhiễm khuẩn), không thể phòng ngừa được bằng một biện pháp đơn lẻ nào mà cần phải có các can thiệp theo tiếp cận rộng, với sự tham gia của nhiều đối tác. Lý do thứ hai là chăm sóc sức khỏe sơ sinh vẫn chưa được quan tâm đúng mực ở hầu hết các nước trên toàn cầu [2].

Với thực trạng đó, vào năm 2015 Tổ chức Liên hiệp quốc (UN) khẳng định rằng đã đến thời điểm tất cả các quốc gia cần dành sự quan tâm đặc biệt cho trẻ sơ sinh [3]. Chính vì vậy tiêu chí giảm TVSS đã được đưa vào mục tiêu 3.2.1 trong các mục tiêu phát triển bền vững (SDGs) "không có trẻ sơ sinh và dưới 5 tuổi chết do các bệnh có thể phòng tránh được" vào năm 2030 [4].
Bài tổng quan này được thực hiện với mục tiêu rà soát lại xu hướng về TVSS trong giai đầu thực hiện mục tiêu 3.2.1 trong SDG 3 trên thế giới và Việt Nam. Số liệu thu được sẽ là những bằng chứng giúp các nhà hoạch định chính sách trong lập kế hoạch cho các can thiệp phù hợp, giảm tử vong sơ sinh ở Việt Nam.

\section{XU HƯỚNG GIẢM TỬ VONG SƠ SINH TRÊN THẾ GIỚI SAU NĂM 2015}

Trong giai đoạn thực hiện MDG (1990 - 2015), sức khỏe sơ sinh ở hầu hết các nước trên thế giới đã có một số cải thiện. Tỷ suất TVSS giảm 47\% (từ $36 \%$ xuống 19\%o) trong 25 năm thực hiện MDG, tuy nhiên tốc độ giảm chậm và hiện vẫn chiếm tới 44\% tổng số TVTE dưới 5 tuổi. Những năm sau kết thúc MDGs (2015), hàng năm vẫn còn tới khoảng 2,7 triệu trẻ sơ sinh tử vong [5].

Tử vong sơ sinh không những giảm chậm mà còn có sự khác biệt rất lớn giữa các quốc gia, khu vực và vùng lãnh thổ. Sự khác biệt này là một thách thức lớn chưa cải thiện được trong mấy thập kỷ qua. Tỷ suất TVSS cao nhất (31/1000) ở Tây Phi, Trung Phi và Nam Á, cao gấp hơn hơn 10 lần so với các nước phát triển. Số tử vong chỉ riêng 3 khu vực này chiếm hơn $1 / 3$ tổng số TVSS trên thế giới [6].

Để có thêm các nỗ lực giảm gánh nặng tử vong sơ sinh trên toàn cầu, chỉ số giảm tử vong sơ sinh đã được đưa vào trong các mục tiêu về sức khỏe của SDGs. Với chỉ tiêu là đến năm 2030, giảm tử vong sơ sinh xuống dưới $12 / \%$, chắc chắn là rất nhiều nước phải có những cố gắng vượt bậc mới có thể đạt được [4]. 
Từ sau kết thúc MDGs đến nay, TVSS chưa có thay đổi gì đáng kể. Số liệu năm 2019 cho thấy tỷ suất TVSS chung cho toàn cầu là $18 \%$ o tương ứng với khoảng 2,5 triệu trẻ tử vong. Như vậy, trung bình mỗi ngày vẫn có tới khoảng 7000 trẻ tử vong khi chưa đầy tháng tuổi. So với tốc độ giảm TVTE dưới 5 tuổi, TVSS giảm hàng năm vẫn chậm hơn nhiều (3,6\% so với 2,6\%/năm) [7]. Theo dự báo của WHO, với tỷ suất TVSS duy trì mức hiện tại sẽ có 27,8 triệu trẻ sơ sinh chết trong trong khoảng từ năm 2018 đến 2030. Các nguyên nhân chính gây tử vong sơ sinh bao gồm Đẻ non; Ngạt; Nhiễm khuẩn và Dị tật bẩm sinh. Phần lớn TVSS (75\%) xảy ra trong tuần đầu và $40 \%$ số trẻ tử vong trong ngày đầu. Vi vậy, chăm sóc cuộc đẻ, hồi sức cấp cứu trẻ ngạt đóng vai trò quyết định trong các can thiệp giảm tử vong sơ sinh [8].

Phân tích tình hình giảm tử vong trẻ em ở 195 nước cam kết đạt SDGs, UNICEF nhận định là với xu hướng bày sẽ có khoảng hơn 60 nước không đạt được mục tiêu về giảm tử vong sơ sinh. Vi thế, cần phải có nhiều nỗ lực hơn nữa cho các can thiệp giảm TVSS, và đó cũng là yếu tố quyết định để thành công trong giảm tử vong trẻ dưới 5 tuổi là chỉ tiêu trong mục tiêu sức khỏe trẻ em của SDG 3 [9].

Có nhiều yếu tố liên quan đến tử vong sơ sinh như phát hiện dấu hiệu bệnh và đưa trẻ đến cơ sở y tế chậm, điều kiện giao thông khó khăn, hệ thống vận chuyển cấp cứu không đảm bảo an toàn. Các yếu tố liên quan mang thai và cuộc đẻ bao gồm không có người đỡ đẻ có kỹ năng hỗ trợ khi sinh, các trường hợp đẻ tại nhà, hạn chế trong tiếp cận với dịch vụ chăm sóc trước, trong và sau khi sinh. Tại cơ sở y tế, cơ sở vật chất nghèo nàn, thiếu trang thiết bị và thiếu cán bộ có kỹ năng cấp cứu sơ sinh được nhiều nghiên cứu khẳng định là những yếu tố liên quan trực tiếp đến tử vong trẻ sơ sinh [10].

Ảnh hưởng của các dịch bệnh mới nổi: Dịch bệnh luôn ảnh hưởng đến cả hệ thống y tế, đặc biệt là thiếu trầm trọng các dịch vụ khám chữa bệnh do tăng đột biến số người mắc bệnh và tử vong. Trong vài thập kỷ nay, có 2 dịch bệnh gây ảnh hưởng lớn đến sức khỏe, đình trệ sự phát triển kinh tế, xã hội, đó là dịch Ebola ở châu Phi và nặng nề hơn rất nhiều là dịch bệnh Covid -19 hiện nay trên toàn cầu.

Trong suốt giai đoạn dịch Ebola ở Tây Phi 2014-2016, các dịch vụ về chăm sóc bà mẹ và trẻ em đã bị giảm sút nghiêm trọng. Phụ nữ không được chăm sóc đầy đủ trong thời gian mang thai và sinh đẻ do hạn chết tiếp cận với các chăm sóc y tế. Tại các cơ sở y tế trang thiết bị, thuốc và các dịch vụ chăm sóc cho bà mẹ, trẻ sơ sinh thiếu thốn do phải tập trung phòng, chống dịch bệnh. Hậu quả là tỷ lệ tử vong mẹ, thai chết lưu và TVSS tăng rõ rệt. Một nghiên cứu ở Sierra Leone cho thấy sau vụ dịch tỷ lệ tử vong mẹ tăng $34 \%$ và tỷ lệ thai chết lưu tăng 24\%[11].

Đại dịch Covid-19 được phát hiện lần đầu tiên ở Vũ Hán, Trung Quốc và nhanh chóng lan rộng ra toàn câu, tác động nghiêm trọng cả về sức khỏe, kinh tế và xã hội. ở các nước thu nhập thấp và trung bình, ảnh hưởng của Covid- 19 thường nặng nề hơn do không có đủ nguồn lực cũng như trang, thiết bị bảo đảm cho các chăm sóc thiết yếu. Dựa trên kết quả đánh giá ảnh hưởng từ vụ dịch Ebola ở Tây Phi, Dorit và cs. đã phân tích tác động gián tiếp của Covid-19 tại 4 nước Ấn Độ, Indonesia, Nigeriavà Pakistan và khẳng định là với tình trạng sử dụng các dịch vụ chăm sóc như hiện tại thì trong 1 năm tới tỷ lệ tử vong mẹ, sơ sinh và thai chết lưu trong 4 nước trên sẽ tăng lên một cách đáng kể. Ước tính sẽ có thêm 31.980 tử vong mẹ, 395.440 tử vong sơ sinh và 338.760 thai chết lưu, tương ứng mức tăng thêm là $31 \%$ số tử vong trong 12 tháng tới [12].

\section{HIÊN TRANG VỀ TỬ VONG SƠ SINH Ở VIẸTT NAM}

Cũng tương tự như tình hình thế giới, tốc độ giảm TVSS chậm hơn nhiều so với tốc độ giảm tử vong ở trẻ dưới 1 tuổi và tử vong ở trẻ dưới 5 tuổi [13]. Vì thế, TVSS vẫn là gánh nặng trong mô hình bệnh tật, tử vong của trẻ em. Theo ước tính mới 
nhất của WHO năm 2019 về TVSS của Việt Nam là $10,5 \%$, thấp hơn số ước tính cho các nước khu vực Đông Nam Á (13\%o) và đã giảm được $9 \%$ so với năm 2014 [14;15].

Tuy TVSS đã có xu hướng giảm nhưng với tỷ suất hiện tại, mỗi năm Việt Nam vẫn có tới khoảng 18.000 trẻ sơ sinh tử vong, chiếm tới $70 \%$ số tử vong trẻ dưới 1 tuổi và $50 \%$ số tử vong trẻ dưới 5 tuổi [16]. Chính vì vậy, giảm tử vong sơ sinh vẫn là một ưu tiên hàng đầu trong các can thiệp cải thiện sức khỏe cho trẻ em.

Nguyên nhân tử vong chính ở trẻ sơ sinh ở nước ta, cũng giống như ở các nước đang phát triển khác, chủ yếu vẫn là ngạt, đẻ non/nhẹ cân, hạ thân nhiệt, hạ đường huyết, dị tật và nhiễm khuẩn $[17 ; 18]$. Cần nhấn mạnh là phần lớn tử vong ở trẻ sơ sinh do các nguyên nhân trên đều có thể phòng tránh được nếu như các can thiệp cứu sống trẻ sơ sinh được áp dụng có hiệu quả ở cả cộng đồng và cơ sở y tế.

Một số thách thức trong cải thiện sức khỏe, giảm tử vong sơ sinh ở nước ta

Sự khác biệt giữa các vùng miền chưa có dấu hiệu thu hẹp: Tử vong sơ sinh rất khác nhau theo các vùng, miền tồn tại nhiều thập kỷ nay và mức độ khác biệt hầu như không thay đổi, thậm chí ở một số vùng còn tăng lên. Trong nghiên cứu ở 14 tỉnh miền núi phía Bắc và Tây Nguyên năm 2009 cho thấy tỷ số TVSS ở vùng núi phía Bắc là $10,3 \%$, cao gấp hơn 2 lần so với vùng Tây Nguyên $(4,4 \%$ ) [17]. Số liệu trong nghiên cứu 7 tỉnh miền núi phía Bắc năm 2015 cho kết quả về sự khác biệt giữa tỉnh cao nhất (Lai Châu) và tỉnh thấp nhất (Bắc Kạn là hơn 3 lần $(17,1 \%$ o so với 5,6\%o) [18]. Sự khác biệt ở tuyến huyện còn rõ rệt hơn như trong nghiên cứu ở 5 tỉnh Tây Nguyên gần đây nhất vào năm 2020cho thấy huyện có tỷ lệ TVSS cao nhất (Tu Mơ Rông) cao đến gấp hơn 60 lần so với huyện thấp nhất (Kư Kuin) (18,4\%o so với 0,3\%o)[19].

Năng lực chăm sóc cấp cứu tại cơ sở y tế chưa đáp ứng được nhu câu: Theo đánh giá của Bộ Y tế và UNICEF, khó khăn trong chăm sóc sơ sinh hiện nay trong nhiều cơ sở y tế là thiếu cả về nhân lực và trang thiết bị, cơ sở vật chất cho chăm sóc sơ sinh. Đặc biệt kỹ năng về cấp cứu sơ sinh ở nhiều cơ sở y tế chưa đáp ứng được nhu cầu, vì thế có nhiều trẻ sơ sinh tử vong do ngạt, suy hô hấp, tuần hoàn vì không được cấp cứu đúng và kịp thời [20]. Nghiên cứu gần đây tại tỉnh Lào Cai cũng cho thấy năng lực của cán bộ y tế về cấp cứu sơ sinh còn hạn chế, đặc biệt là tuyến huyện [21].

Tại gia đình và cộng đồng, các trường hợp đẻ tạinhà không có người có chuyên môn đỡ đẻ; Phát hiện dấu hiệu bệnh và đưa trẻ đến cơ sở y tế chậm; Điều kiện giao thông khó khăn; Chăm sóc vận chuyển cấp cứu không đảm bảo an toàn là những yếu tố chính tăng tử vong sơ sinh.

Nguốn số liệu: Một hạn chế trong đánh giá về sức khỏe sơ sinh là các số liệu về tỷ suất tử vong cũng như các vấn đề bệnh lý về trẻ sơ sinh không có trong báo cáo thống kê của ngành $Y$ tế. Số liệu về sức khỏe sơ sinh được thu thập từ các nguồn nghiên cứu nhỏ lẻ, ở các địa bàn khác nhau, khó kết luận là số chung cho cả nước.

\section{Cơ HộI CAN THIỆP CẢI THIỆN SỨC KHỎE, TĂNG Cơ HộI SỐNG CHO TRẺ SƠ SINH}

4.1. Tiếp cận chăm sóc liên tục từ khi mang thai, sinh đẻ và sau đẻ với chất lượng cao và bao phủ trên diện rộng là các can thiệp hiệu quả giảm tử vong sơ sinh

Hầu hết các tử vong sơ sinh đều có thể phòng tránh được. Gói can thiệp có hiệu quả nhất được nhiều nhà nghiên cứu khẳng định bao gồm bảo đảm cuộc đẻ an toàn (từ khi chuyển dạ và cuộc đẻ); chăm sóc sơ sinh thiết yếu; chăm sóc đặc biệt cho các trẻ nhẹ cân và trẻ bệnh. Một phân tích tổng hợp ở 75 nước trên thế giới có tử vong mẹ và sơ sinh cao nhất năm 2014, ước tính là nếu nâng cao chất lượng, thu hẹp khoảng cách cung cấp các dịch vụ có hiệu quả giữa các CSYT có thể ngăn ngừa 113.000 tử vong mẹ, 531.000 thai chết lưu và 1.325 triệu trẻ sơ sinh hàng năm với chi phí khoảng 0,9 USD/người đến năm 2020. Nếu tăng độ bao phủ và cải thiện chất lượng chăm sóc trước, trong thời gian mang thai, tại cuộc đẻ và sau đẻ thì có 
thể ngăn được $71 \%$ tử vong sơ sinh (1,9 triệu), 33\% thai chết lưu $(0,82$ triệu) và $54 \% \operatorname{TVM}(0,16$ triệu) mỗi năm đến năm 2025. Để giảm được ở mức độ đó, cần tăng chi phí lên 1,5 USD/mỗi người. Chi phí cho can thiệp vào CSYT cao hơn cho cộng đồng nhưng tác động rõ rệt hơn [22].

\subsection{Chăm sóc thiết yếu và hồi sức sơ sinh}

Nhiều nhà nghiên cứu trên thế giới đều khẳng định là chỉ với các can thiệp cơ bản, ít tốn kém cho tất cả cuộc đẻ đã có thể cứu sống được hơn $70 \%$ số trẻ sơ sinh tử vong. Đó là bảo đảm trẻ thở được, giữ ấm, được bú mẹ và được bảo vệ với các thực hành đơn giản có thể thực hiện ở tất cả mọi nơi kể cả những nơi có nguồn lực hạn hẹp nhất, đó là lau khô trẻ ngay sau đẻ; Đặt trẻ nằm da kề da với mẹ; Cắt rốn muộn và cho trẻ bú sớm [23]. Đối với những trẻ có khó khăn với nhịp thở đầu, hỗ trợ trẻ thở, hồi sức sơ sinh đúng có thể giảm được $38 \%$ số trẻ sơ sinh tử vong trong 7 ngày đầu [24].

\subsection{Chăm sóc trẻ đẻ non/nhẹ cân và trẻ sơ sinh bệnh}

Một số nghiên cứu đã cho kết quả chứng minh là chăm sóc trẻ đẻ non và trẻ sơ sinh bệnh có thể làm giảm được $30 \%$ số trẻ tử vong trong 1 tháng đầu đời. Các can thiệp chính là chăm sóc trẻ đẻ non/nhẹ cân bằng phương pháp Kangaroo (KMC); dự phòng và điều trị sớm các bệnh nhiễm khuẩn; phát hiện, xử trí sớm vàng da và phòng thiếu oxy gây tổn thương não liên quan đến cuộc đẻ [25].

Chăm sóc trẻ đẻ non/nhẹ cân bằng phương pháp KMC là một can thiệp có thể áp dụng được ở những nơi nghèo nhất và mang lại hiệu quả cao. Trẻ nằm kề da với mẹ, được ủ ấm, được bú mẹ hoàn toàn và được bảo đảm không nhiễm khuẩn chéo là những lợi ích của phương pháp KMC. Can thiệp này được chứng minh là giảm $40 \%$ tử vong ở trẻ đẻ non/nhẹ cân; $66 \%$ số trẻ bị hạ thân nhiệt và $55 \%$ nhiễm khuẩn bệnh viện [26].

\subsection{Lồng ghép các can thiệp chăm sóc bà mẹ - trẻ sơ sinh}

Mặc dù các can thiệp đơn lẻ được thực hiện đúng và kịp thời đã cứu sống được hàng trăm ngàn trẻ sơ sinh, tuy nhiên lồng ghép thực hiện các can thiệp một cách đồng bộ để có kết quả với chi phí tiết kiệm nhất. Đào tạo nhân viên y tế tăng cường chất lượng cung cấp dịch vụ trong các CSYT cùng với nâng cấp cơ sở, vật chất, trang thiết bị và thuốc đồng thời với giáo dục sức khỏe cộng đồng để có thể phối hợp thành công trong chiến lược cứu sống trẻ. Một số mô hình lồng ghép như hồi sức sơ sinh, xử trí sơ sinh bệnh được đưa vào chương trình làm mẹ an toàn; Lồng ghép xử trí, chăm sóc trẻ bệnh (IMCI) đã được nhiều quốc gia áp dụng.

Lồng ghép các chương trình cũng cần được sự hỗ trợ của cả mạng lưới y tế và cam kết của chính quyền, đặc biệt đối với những can thiệp cộng đồng. Cùng với sự cải thiện nhận thức của người dân tiếp cận với dịch vụ chăm sóc y tế thì việc nâng cao chất lượng tại đây là hết sức cần thiết để đáp ứng nhu cầu của họ và tăng cường tiếp cận chăm sóc liên tục từ gia đình, cộng đồng và sơ sở y tế.

Tóm lại, kết quả nghiên cứu khoa học đã khẳng định là các can thiệp cơ bản theo tiếp cận liên tục kể từ khi chuyển dạ sẽ giảm được $71 \%$ tử vong sơ sinh: $41 \%$ trong giai đoạn chuyển dạ và cuộc đẻ; $30 \%$ đối với các can thiệp chăm sóc đặc biệt cho trẻ đẻ non/nhẹ cân và trẻ sơ sinh bệnh. Với các can thiệp được WHO khuyến nghị hiện tại là chăm sóc bà mẹ mang thai, bảo đảm an toàn trong cuộc đẻ, hồi sức sơ sinh kịp thời đối với trẻ ngạt, chăm sóc sơ sinh thiết yếu, phát hiện và điều trị đúng trạng bệnh lý ở trẻ có thể giảm số tử vong do 3 nguyên nhân chính: đẻ non, ngạt, nhiễm khuẩn theo thứ tự là $58 \%, 79 \%$, và $84 \%$.

\subsection{Môi trường hỗ trợ}

Áp dụng các can thiệp giảm TVSS có hiệu quả vào thực tế sẽ không thành công nếu thiếu môi trường hỗ trợ. Chính sách của nhà nước về chủ trương, nhân lực, tài chính; Sự tham gia của các ban ngành liên quan cùng với ngành $Y$ tế là yếu tố quyết định thành công trong triển khai can thiệp. Hỗ trợ của quốc tế và các đối tác trong và 
ngoài nước đóng vai trò hết sức quan trọng trong chuyển giao kinh nghiệm, kỹ thuật, đồng hành và thúc đẩy các hoạt động can thiệp. Điều phối, lồng ghép các can thiệp chăm sóc sức khỏe bà mẹ, trẻ em và trẻ sơ sinh sẽ tạo nên nguồn lực tiềm tàng trong quá trình can thiệp giảm TVSS.

\section{KẾT LUẬN}

Để có thể đạt được mục tiêu về sức khỏe trong SGDs ở tất cả các quốc gia ký cam kết, can thiệp có tính chất quyết định là giảm TVSS. Các can thiệp cần được thực hiện theo tiếp cận liên tục theo thời gian từ khi mang thai, tại cuộc đẻ và sau đẻ đồng thời với liên tục theo địa điểm trong mạng lưới chăm sóc sức khỏe từ gia đình, cộng đồng và cơ sở y tế. Gói can thiệp cơ bản, hiệu quả nhất bao gồm chăm sóc chăm sóc bà mẹ trong thời gian mang thai, chuyển dạ; Chăm sóc thiết yếu cho bà mẹ, trẻ sơ sinh tại cuộc đẻ, ngay sau khi đẻ và chăm sóc đặc biệt cho các trẻ sơ sinh đẻ non/nhẹ cân và trẻ bệnh.

\section{TÀI LIÊU THAM KHẢO}

1. You D, Hug L, Ejdemyr S, Idele P, Hogan D, Mathers $C$, et al. Global, regional, and national levels and trends in under- 5 mortality between 1990 and 2015, with scenario-based projections to 2030: a system - atic analysis by the UN Inter agency Group for Child Mortality Estimation. Lancet. 2015; 386: 2275-2286.

2. United Nations Children's Fund (UNICEF), 2018. Every child alive- The urgent need to end newborn deaths.

3. WHO and UNICEF 2019. SURVIVE and THRIVE. Transforming care for every small and sick newborn.

4. UN. Department of Economic and Social Affairs. Sustainable Development Goals (SDGs)

5. UNICEF. Committing to Child Survival: A Promise Renewed Progress Report 2015.

6. UNICEF (2019). Child Mortality Estimates. Estimates generated by the UN Inter-agency
Group for Child Mortality Estimation (UN IGME).

7. UNICEF 2019. Neonatal mortality. UNICEF Data: Monitoring the situation of children and women.

8. UNICEF 2019. Child survival and the Sustainable Development Goals (SDGs).

9. WHO 2019. Newborns: Reducing mortality.

10. Kim E Dickson et al. Every Newborn: health - systems bottlenecks and strategies to accelerate scale-up in countries. The Lancet. Volume 384, No. 9941, p438-454, 2014.

11. Jones SA, et al. Women and babies are dying but not of Ebola': the effect of the Ebola virus epidemic on the availability, uptake and outcomes of maternal and newborn health services in Sierra Leone. BMJ Glob Health 2016;1: e000065. doi: 10.1136/bmjgh-2016-000065.

12. Dorit Stein, Kevin Ward, and Catherine Cantelmo. Estimating the Potential Impact of COVID-19 on Mothers and Newborns in Low- and Middle-Income Countries. Health Policy Plus. 2020.

13. Bộ Kế hoạch đầu tư. Nước CHXHCN Việt Nam. Báo cáo quốc gia kết quả 15 năm thực hiện các mục tiêu MDG.

14. Tổng cục Thống kê- UNICEF 2014. MICS 4.

15. WHO. Viet Namkey indicators.

16. Vụ SKBM-TE, Bộ Y tế. Báo cáo năm 2019.

17. Bộ $Y$ tế. Chương tình giảm TV mẹ và Sơ sinh 2009. Nghiên cứu thực trạng TVM và TVSS tại 14 tỉnh tham gia chương trình.

18. Bộ $\mathrm{Y}$ tế 2015. Dự án hỗ trợ $\mathrm{y}$ tế các tỉnh miền núi phía Bắc - Báo cáo kết quả điều tra TVM và Sơ sinh tại 7 tỉnh miền núi phía Bắc.

19. Trung tâm nghiên cứu môi trường và sức khỏe 2020. Dự án chăm sóc sức khỏe nhân dân các tỉnh Tây Nguyên - Báo cáo điều tra TVM và Sơ sinh tại 5 tỉnh Tây Nguyên.

20. Bộ Y tế (2013). Phân tích về các rào cản trong chăm sóc sơ sinh ở Việt Nam. 
21. Sở Khoa học công nghệ Lào Cai và Bệnh viện Nhi Trung ương. Đánh giá thực trạng cấp cứu, tử vong sơ sinh và đề xuất một số giải pháp nâng cao năng lực cấp cứu tại tỉnh Lào Cai.

22. Bhutta, Z.A., et al., Can available interventions end preventable deaths in mothers, newborn babies, and stillbirths, and at what cost? Lancet, 2014.

23. WHO - Essential Newborn Care Course.
24. Amuchou $S$ et al. Neonatal Respiratory Care in Resource-Limited Countries. Assisted Ventilation of the Neonate (Sixth Edition), 2017. 25. UNICEF 2019. Newborn Care - UNICEF Data.

26. Conde-Agudelo A, Belizán J M, Diaz Rossello J. 2014. “Kangaroo Mother Care to Reduce Morbidity and Mortality in Low Birthweight Infants." Cochrane Database of Systematic Reviews (4): CD002771. doi: 10.1002/14651858. CD002771.pub3. 